\title{
What Would Student-Based Allocation Mean for Pennsylvania School Districts?
}

\section{MARGUERITE ROZA}

Georgetown University

AMANDA WARCO

Georgetown University

In recent months, policymakers across the country have been exploring state school financing formulas with the goals of promoting equity, transparency, and adequacy. Toward that end, state leaders are considering a new model for disbursing state education funds called "student-based allocation" (SBA)-one that would allocate funds on the basis of students. In fact, many states already have some sort of formula using students as the basis, although in practice, most essentially use a hybrid set of allocations such that the portion of funds allocated on the basis of students varies substantially across states. This analysis of 14 states shows that among the sampled states, between 0 and $85 \%$ of all state and local funds is allocated on the basis of students. In Pennsylvania, after operating in the absence of a formal allocation formula for several years, the Basic Education Funding Commission (BEFC) was tasked with recommending a new finance scheme for funding the state's schools. In this paper, we outline the rationale behind SBA and investigate the extent to which the BEFC proposal would allocate funds on the basis of students.

ne of a state's primary responsibilities is to divide up the public funds for K-12 schooling. Each state has a set of finance policies that together determine how the state and local funds are allocated so that districts can then apply them to schools and classrooms. Different states 
use a host of variables, formulas, and other mechanisms to determine how much each district receives. Because of the tremendous political lift involved in changing state formulas, they don't change much from year to year. Rather, states tend to layer new program funds on to the old model, or make minor tweaks here or there to address the greatest pain points. Eventually, a formula may seem broken enough that a state tackles it from top to bottom.

Such appears to be the case in Pennsylvania, where a State Commission (called the Basic Education Funding Commission, or the BEFC) was tasked with developing a whole new state education funding formula. Of interest in Pennsylvania is a mechanism called "student-based allocation" (SBA), also known as weighted student funding (WSF). With SBA, state (or state and local) funds are deployed on the basis of students and student types (poverty, disability, etc.). SBA has garnered interest among state leaders largely for its promise to improve equity and transparency, while ensuring that districts with higher needs students receive appropriately higher allocations. Further, as state leaders face both increasing costs and highly constrained resources, some state leaders are seeking SBA as a means to facilitate greater productivity and financial sustainability in their state education systems.

In this paper, we outline the rationale behind SBA and investigate the BEFC proposal against that rationale. Drawing on data from Pennsylvania and other states' SBA systems, we compare Pennsylvania's current and proposed allocations to those of 14 other states. And we analyze what the BEFC proposal would mean for the relative share of state funding allocated according to student versus district characteristics.

\section{State Leaders Look to SBA to Enhance Equity and Productivity}

The specifics of state funding formulas vary widely. But what many states have in common is incremental layers of formula iterations that can unintentionally work to create inequities among districts, hinder efficient use of public funds, and inhibit system-wide productivity. As states rethink their allocation systems, many are considering student-based allocation as a way to tackle these three challenges.

Student-based allocation emerged in the United States two decades ago as a means for large districts to better deploy funds to schools. ${ }^{1}$ The funding formula is student driven: A fixed dollar amount is set for each student type and funds flow on the basis of students, with higher-needs students generating incrementally more money. The funds remain flexible so that each locale can spend them as needed. This formula departs from traditional district 


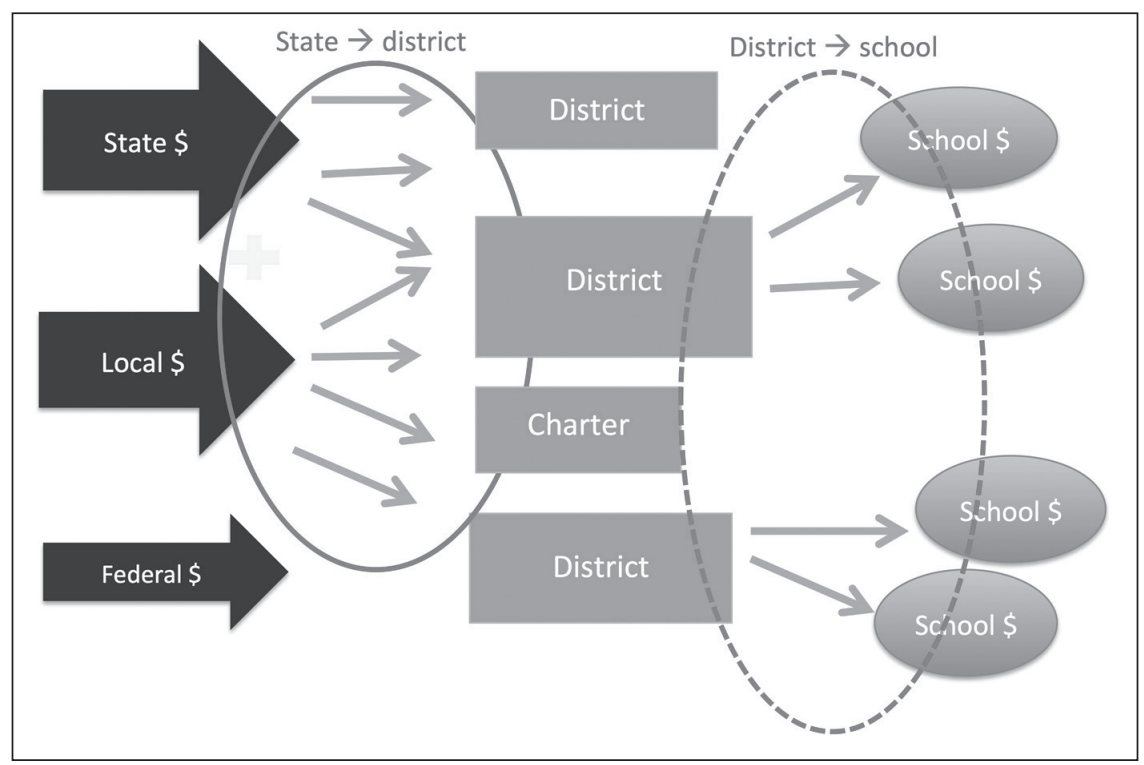

Figure 1. SBA Can Be Used to Deploy Funds at Different Levels in the System. (Image created by authors.)

allocations that tend to assign positions to schools (one teacher for every 25 students, one counselor for every 300 students, etc.). Big districts like Houston, Boston, Baltimore, Denver, Cleveland, Chicago, and others now use SBA at the district level to distribute funds to schools.

More recently, state leaders have taken an interest in using SBA to push state (or combined state and local) funds to districts (or directly to schools) as illustrated in Figure 1. While some states do allocate a foundational per-pupil payment (a foundation formula), what sets SBA apart is that student need drives the variation in the fixed per-student amounts paid out. And that weighted formula replaces a range of ways that states are funneling dollars to districts and schools beyond just their basic formula. For instance, some states drive funding for high-needs students through categorical allocations or designated program funding (such as funds for reading coaches, graduation specialists, and so on). Separate state allocations are often layered on for designated efforts for STEM initiatives, teacher bonuses, AP coursework, textbooks, and much more, creating opaque and complex allocations that may work to undo any equitable distribution created by the basic formula. Other states lean on funding formula mechanisms like hold-harmless provisions for enrollment decline, ${ }^{2}$ adjustments for size and urbanicity, or to offset charter school growth. Several states like Delaware and Idaho don't use a foundation formula at all, but rather allocate staff positions based on student enrollment 
(and then reimburse districts for actual salaries of the allowable staff counts) or use some other arrangement altogether (like a grandfathering formula, where all districts get some percentage of their previous year's allocation regardless of changes in the number of students served or the mix of student needs). ${ }^{3}$

SBA has surfaced as a solution to frustrations with existing state allocation formulas, which have been criticized for being

- complex, opaque, and unfair

- too prescriptive, inflexible and onerous in terms of compliance

- inequitable because districts get uneven revenues (often driven by the interplay of local and state monies) and districts with greater student needs don't receive sufficiently greater resources to meet their students' challenges

- inefficient and unproductive, since current formulas protect districts from making needed adjustments to changing enrollments or conditions

Proponents say SBA simultaneously addresses the complexity (district leaders know that an English language learner will generate \$X allocation, a homeless student will generate \$Y), flexibility (schools can individualize resources to match their staff and students' strengths and needs), and equity concerns (students with greater needs trigger larger allocations).

Further, SBA is thought to replace policies that are considered inefficient with policies that promote productivity-enhancing adaptations. A criticism of some existing funding formulas is that they fund "phantom students" by delivering more funds to districts than would be justified by their actual enrollment (Roza and Fullerton 2013). These policies can take the form of

- extra funds for declining enrollment districts

- offsets for districts that lose students to charters

- small districts subsidies

- minimum allotments for categorical allocations

In each case, the affected districts receive funds in excess of what they would receive if only the students on their rolls were funded. All told, these kinds of provisions drive more funds to some districts than are warranted under the total state enrollment figures and corresponding lower per pupil allotments for all other districts (assuming limited state funds). Hold-harmless provisions, for instance, are also thought to insulate district leaders from making the adaptive (and therefore productivity-enhancing) changes (such 
as right-sizing, but also adopting new delivery models) needed to better meet the size of the shrinking student rolls. In other words, the policies intended to "protect" these districts may be enabling a more sluggish response to changes that should be happening with enrollment fluctuations.

Nudging districts toward greater adaptability-the thinking goes-is important in a labor-intensive sector where costs will likely outstrip revenues in coming years. With labor costs rising faster than revenue streams, schooling could suffer from steady decline over successive years of incremental cuts, provided that services remain stuck in a fixed delivery model that doesn't adapt to the kinds of changes that have fueled productivity improvements in other service sectors (Roza 2013). In order to make productivity improvements, districts need to seek new delivery models that allow schools to do the most with scarce, but fairly allocated, resources.

In California, state leaders recently replaced a reportedly complex and onerous system of categorical funding with a student-based formula called the Local Control Funding Formula (LCFF). ${ }^{4}$ For each district, the state determines the target spending, based on the mix of students and student types, and then applies the expected local funds toward that target. State funds then make up the difference. (Table 1 shows how much is allocated for each student by grade level and need.) Districts then have flexibility in how they apply funds, and then own the corresponding responsibility for improved outcomes. LCFF isn't a pure SBA model, however, as state leaders did leave a pool of funds in a hold-harmless provision to protect some districts from large losses in the first few years of implementation.

\begin{tabular}{|l|l|}
\hline \multicolumn{2}{|l|}{ Table 1: California's Student-Based Allocation Formula } \\
\hline Student Types* & Allocation \\
\hline Grades K-3 & $\$ 7,557$ \\
\hline Grades 4-6 & $\$ 6,947$ \\
\hline Grades 7-8 & $\$ 7,154$ \\
\hline Grades 9-12 & $\$ 8,505$ \\
\hline & \\
\hline Limited English & $+20 \%$ \\
\hline Poverty $\dagger$ & $+20 \%$ \\
\hline Foster youth & $+20 \%$ \\
\hline $\begin{array}{l}\text { Source: Data from California Department of Education, “Local Control Funding Formula Overview," } \\
\text { last reviewed November 25, 2015, accessed February 11, 2014. } \\
\text { * In California, students receive the weight only once even if they fall into multiple categories. Often, } \\
\text { in other state formulas, students receive the weight amount for each category that applies to them. } \\
\text { †High-poverty districts are also awarded a 50\% weight for each poor student above 55\%. }\end{array}$ \\
\hline
\end{tabular}


A similar model was proposed in Colorado, but the Colorado formula was tied to a ballot measure that was defeated at the ballot box in 2013. ${ }^{5}$ In the last three years, leaders in Ohio, Illinois, Georgia, Arizona, and Delaware have also made proposals to advance student-based allocation, and in some cases those are still pending. ${ }^{6}$

\section{Concerns about Flexibility and Districts' Adaptability to Changes}

This policy proposal is not without skeptics. Some worry that with greater local flexibility, districts would still yield to pressures from advantaged parents, unions, or other forces to spend money unwisely or in ways that ill serve the most disadvantaged students.

Others remain concerned that, since a student-based formula only funds students, it isn't sensitive enough to differences in districts created by nonstudent factors. For instance, SBA formulas don't take into account the historic district enrollments (for shrinking districts), charters, small size, high transportation costs, etc. Skeptics worry that districts with these and other characteristics may be less equipped to serve students with the available funding. And finally, some worry that, if not clearly defined or limited, districts may have an incentive to over-identify certain types of students.

\section{Pennsylvania's BEFC Tasked with Devising a More Sustainable State Allocation Formula}

Plenty has been written about how Pennsylvania's existing formula isn't a formula at all. ${ }^{7}$ At one point, Pennsylvania did have a student-based formula on the books, but it hasn't been used in several years. Rather, recent years' state funding has been allocated by just adding a percentage each year to whatever each district received the year before, regardless of any changes in student rolls. Not surprisingly, growing districts are seeing per pupil allocations fall, while districts that have lost students are now funded at higher per pupil allocations.

Other changes in student needs are also not considered, including the rapid rise in the percentage of students in poverty. As the BEFC reports, the percentage of students eligible for free or reduced lunch has risen from 35\% to $48 \%$ over the last decade (Basic Education Funding Commission 2015). Given the higher needs associated with these student characteristics, districts are understandably concerned about a state formula that ignores these changing student needs.

Much of the back and forth in Pennsylvania has also concerned the overall level of state funding and its interactions with local money. This paper 
doesn't tackle the question of how much money was or would be put into the state formula, but rather focuses on the means of deploying it. However, also at issue is the constant worry that state sources will remain insufficient to meet the rising cost factors in Pennsylvania's districts. In Pennsylvania, like in other states, labor costs are outpacing state revenues, forcing tradeoffs within districts that put pressure on the financing model. For instance, from 2004 to 2008 , the benefits load on salaries (a number that should remain fixed if benefits were growing at the same rate as salaries) jumped from $30 \%$ to $37 \% .{ }^{8}$ With cost pressures mounting, and given the constrained nature of state funds, there is pressure for the state system to fund schooling in a way that helps promote productivity improvements.

\section{The BEFC Proposal Would Deploy Funds by Both Student and Nonstudent Factors}

Given the above conditions, the BEFC considered SBA for the state. In the summary report, the BEFC makes a proposal for a hybrid state allocation formula that involves divvying up state monies in ways that include elements of student-based allocation, while also driving a portion of funds to districts on the basis of nonstudent factors: ${ }^{9}$

a. Student-based factors include poverty and English proficiency. As the BEFC has outlined, poverty is a student factor relevant to learning. The BEFC's formula includes three types of poverty weights to take into account varying levels and concentration of poverty. Similarly, students with limited English proficiency are awarded an additional $60 \%$ allocation.

b. The formula recognizes local revenue capacity. Whereas a SBA model could include local funds in its generation of a per pupil allocation, the BEFC formula applies a local income and capacity index (an index designed by the BEFC that takes into account district median income and property tax wealth), which works similarly to channel more funds to those districts with less local wealth.

c. The BEFC's formula insulates districts from changing enrollment and corresponding financial implications. Rather than base allocations on actual current year student counts-as a pure SBA formula would-the BEFC bases allocation on a rolling three-year average. In doing so, districts with declining enrollment are funded for more students than actually attend the district, while some are not receiving funds for all the students on their rolls in a given year. 
The BEFC's rationale is to protect declining enrollment districts, but at the same time, that adjustment for "phantom" students means declining enrollment districts aren't making the year-toyear adaptations justified by their enrollment changes.

d. The BEFC channels higher per pupil amounts according to district characteristics. In the SBA design, district characteristics aren't weighted, only student ones. The BEFC formula, however, factors in some district characteristics to its formula, including size, sparsity, and attendance at charters. ${ }^{10}$ The result is that the dollar amount generated for a third grade student with limited English proficiency in one district is different from that generated to a student with the same characteristics in another district.

\section{The BEFC Proposal Yields 37\% of Funds Driven on the Basis of Pupils}

The BEFC proposed formula, like those in other states, contains some elements of a student-based allocation system, and yet has some funding factors that don't involve student types. Given that most states are some hybrid of different funding formula types, ${ }^{11}$ our team has been conducting an ongoing study (thus far in 14 states) to measure the portion of state and local monies delivered via student-based allocation. ${ }^{12}$ Measuring progress toward full student-based allocation can inform state policymakers as they take stock of the current finance policies and set goals for future policies.

The study analyzed all state and local funds in each state and determined the portion of any state and local funds deployed with a student-based formula. To be considered student based, the allocation had to deploy a fixed amount of money on the basis of students or student types. The study considered all state and local public funds for K-12 education, excluding any long-term obligations like debt for facilities. ${ }^{13}$ The study then investigated the percentage that would be allocated if Pennsylvania swapped its current allocations and instead deployed all its funds using the BEFC-proposed formula. ${ }^{14}$

Figure 2 captures the findings for each of the 14 states including Pennsylvania's allocations both in the current form and using the BEFC formula for all allocations. As is evident in the figure, states vary widely on the portion of funds delivered on a student basis. New Jersey, California, and Minnesota all distribute more than $75 \%$ of the state and local funds on a student basis. Delaware, Idaho, Tennessee, and Washington have low percentages, since these states deliver funding primarily through a staffing formula.

At present, none of the funds in Pennsylvania's existing model are deliv- 


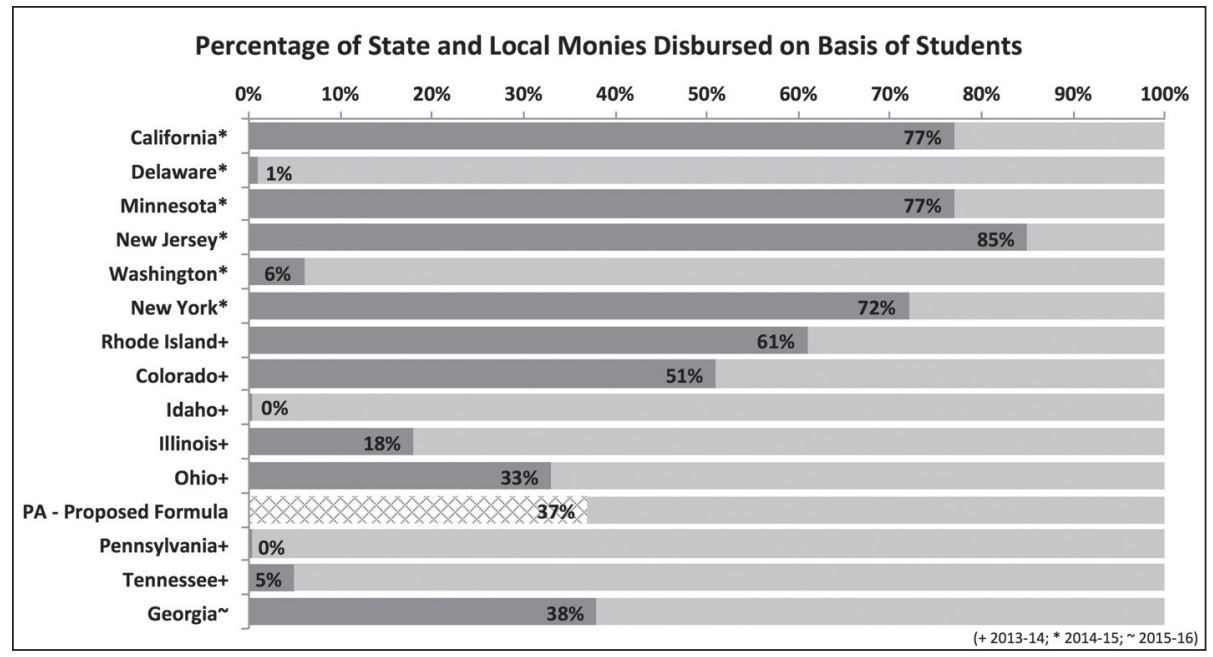

Note: Reported figures augment analysis initially reported by Miller, Roza, and Simburg 2014 with authors’ analysis based on publicly available state and local education funding sources, legislative language, and allocation reports.

Figure 2. Portions of State and Local Education Funds Delivered via SBA. (Image created by authors.)

ered via SBA (hence the $0 \%$ ), as the state is essentially utilizing a hold-harmless mechanism. If the state instead adopted the BEFC formula for all its funding, that percentage would jump to $37 \%$. Relative to the other SBA states, that figure is low, although a substantial increase over its current figure of $0 \%$.

Why does the BEFC proposal only yield $37 \%$ of the funds delivered via SBA? The nonstudent factors, such as charters and district size, are partly to blame. A pure student-based formula would ignore district size and the school type, and fund only the students. The responsibility for the district, then, would be to craft delivery models that were more suited for smaller enrollments or could transfer those same per pupil allotments to charters. Some schools already do this, relying on staff with multiple roles. For instance, a principal of a small school might also teach a class, or instead of a full time gym teacher or nurse, the school might contract with a personal trainer or nursing service in order to buy services in smaller increments.

Another reason that the BEFC formula doesn't yield a higher percentage of funds delivered via SBA is that its basis is on the three-year rolling enrollment average and not actual current year enrollment. And finally, the BEFC doesn't use a student basis for counting local funds toward its formula allocation (rather, it uses a local capacity index). The result is that local funds together with state funds don't generate a predictable dollar amount for a particular student type. That dollar figure will continue to vary by district. 


\section{A Window of Opportunity in Pennsylvania}

The reason that state education finance formulas stay in place for decades is that the politics are challenging. Education tends to be the largest item in state budgets, and every locale has something to gain or lose with a potential formula overhaul. At the same time, when the window for change opens, legislators have an enormous responsibility as the next formula will likely be in place for decades into the future.

No one can say for certain what schooling will look like two decades from now, let alone understand how cost structures will be redefined. For instance, will population density be a moot factor given technological changes that might be able to group students in a shared course miles apart? Will the school year be redefined and staffing roles dramatically altered? For state leaders, designing an allocation system amid such uncertainty is tricky, particularly given that so many years may pass before there is the opportunity to modify the system. But the one thing we know will still be there in two decades are the students. Aligning money with the students offers some promise that a finance formula will be able to stand the test of time.

As Pennsylvania's leaders continue to explore solutions to its ongoing state financing issues, this is the moment to take stock of both the opportunity and the extent to which proposals meet the state's long-term goals. We can expect that leaders will have different opinions on what's best for Pennsylvania, and for how districts should be expected to operate with public funds. This analysis compares the existing and proposed state models with those in other states, to illustrate the range of solutions being generated in states across the country. As leaders size up their options and make decisions about the future of Pennsylvania's education-finance formula, understanding the scope and implications of the proposals before them is critically important.

\section{NOTES}

1. For a more complete history and description on WSF, see Roza 2014.

2. Here we refer to "hold-harmless provisions" as provisions that states include to prevent a year-to-year decrease in funds to a district. Most often such hold-harmless provisions work to ensure that a district's total funding level doesn't dip below the previous years' level, despite decreases in actual student enrollment. For further discussion of the impact of this type of hold-harmless, please see "Funding Phantom Students" (Roza and Fullerton 2013).

3. For instance, Pennsylvania's formula does not take into account enrollment at all, but rather works as a uniform percentage adjustment to the previous year's funding level.

4. See Freedberg 2013.

5. Simpson 2013.

6. See, for example, Smith and Snell 2015 and Illinois Business Journal 2015. 
7. For one example, see "Pennsylvania’s Historic School Funding Problem” (Pennsylvania 2015).

8. Author's calculations based on National Center for Education Statistics data from 2004 to 2008. For additional discussion of rising labor costs see the BEFC final report including testimony from Marguerite Roza on page 24.

9. Pennsylvania created a similar task force in 2013 to study the state's approach to special education funding. That task force ultimately made recommendations to use a formula that would create three funding tiers for special education students (based on what districts had been spending on those students in previous years) and adjust that funding according to district-based characteristics. In 2014-2015, the state amended the funding formula to allocate $\$ 19.8$ million through the new formula. Since the formula amounts were tied to the previous years' funding levels, it is not student based. The BEFC was tasked with revising the Basic Education Funding calculation only, which does not include the special education funding.

10. Charter schools are public schools that operate independently of school districts. Approaches to funding charter schools vary across states. In Pennsylvania, charter schools receive their funding through the district. BEFC mistakenly considers percentage of district attendance in a charter in their weighted student formula as a "student" characteristic, rather than a characteristic of the district.

11. Hawaii is the closest to a pure SBA model, although the state has only a single district.

12. See an earlier reporting on a portion of these findings in Miller, Roza, and Simburg 2014 .

13. Federal funds, which represent $9-12 \%$ of total $\mathrm{K}-12$ revenues, were excluded from this analysis, as were funds for long-term debt and capital costs.

14. Note that at the time of writing the legislature was not considering adopting the BEFC formula for all its funds, so the model here is a hypothetical policy model for future years.

\section{REFERENCES}

Basic Education Finance Commission. 2015. Report and Recommendations. http://basic educationfundingcommission.pasenategop.com/files/2014/08/final-report-061915 -.pdf (March 8, 2016).

Freedberg, Louis. 2013. "Reform of California's School Finance System Likely.” EdSource, June 4. http://edsource.org/2013/governor-brown-eyes-yet-another-education-victory /32907 (March 8, 2016).

Illinois Business Journal. 2015. "Manar, Others Detail Proposed Changes to Education Funding in Illinois.” February 7. http://www.ibjonline.com/localheadlines/1670manar-others-detail-proposed-changes-to-education-funding-in-illinois (March 8, 2016).

Miller, Larry, Marguerite Roza, and Suzanne Simburg. 2014. "Funding for Students' Sake: How to Stop Financing Tomorrow's Schools Based on Yesterday's Priorities.” The SEA of the Future 3 (May): 19-31.

Pennsylvania School Funding Project. 2015. Pennsylvania's Historic School Funding Problem. http://www.paschoolfunding.org/the-problem/pennsylvania\%E2\%80\%99s-his toric-school-funding-problem/ (March 8, 2016).

Roza, Marguerite. 2013. "Leveraging Productivity for Progress: An Imperative for States." The SEA of the Future 2 (May): 8-17. 
_. 2014. "Weighted Student Funding." In Encyclopedia of Education Economics and Finance, ed. Dominic J. Brewer and Lawrence O. Picus. Los Angeles: Sage Publications, 835-838.

Roza, Marguerite, and Jon Fullerton. 2013. "Funding Phantom Students." Education Next 13 (3): 8-16.

Simpson, Kevin. 2013. "Voters Reject Big Tax Hike, School Finance Measure Amendment 66." Denver Post, November 5. http://www.denverpost.com/breakingnews/ ci_24462841/voters-reject-big-tax-hike-school-finance-measure (March 8, 2016).

Smith, Aaron, and Lisa Snell. 2015. "Moving toward Transparent and Student-Based Funding Reform in Georgia." Georgia Public Policy Foundation, December 4. http:// www.georgiapolicy.org/2015/12/moving-toward-transparent-and-student-basedfunding-reform-in-georgia/ (March 8, 2016). 